\title{
The Role of Procalcitonin in the Diagnosis and Prognosis of Severe Surgical Patients with Sepsis
}

\author{
Zheng D. ${ }^{1}$, Liu N. ${ }^{2}$, Ma J. ${ }^{3}$, Chen L. ${ }^{4}$, Tai Q. ${ }^{5}$, Xu G. ${ }^{6 *}$ \\ DOI: https://doi.org/10.17511/ijmrr.2019.i02.07 \\ 1 Donghua Zheng, Department of Critical Care Medicine, The First Affiliated Hospital, Sun Yat-sen University, Guangzhou, Guangdong, \\ China. \\ 2 Na Liu, Department of Critical Care Medicine, The First Affiliated Hospital, Sun Yat-sen University, Guangzhou, Guangdong, China. \\ 3 Jianhui Ma, Department of Critical Care Medicine, The First Affiliated Hospital, Sun Yat-sen University, Guangzhou, Guangdong, China. \\ ${ }^{4}$ Li Chen, Department of Critical Care Medicine, The First Affiliated Hospital, Sun Yat-sen University, Guangzhou, Guangdong, China. \\ 5 Qiang Tai, Department of Critical Care Medicine, The First Affiliated Hospital, Sun Yat-sen University, Guangzhou, Guangdong, China. \\ 6* Guixing Xu, Department of Critical Care Medicine, The First Affiliated Hospital, Sun Yat-sen University, Guangzhou, Guangdong, China.
}

Purpose: To investigate the clinical significance of serum procalcitonin (PCT) concentrations and related indicators of infection in the early diagnosis and prognosis of severe surgical patients with infection. Methods: This study included 77 critically ill patients taken from the Surgery Department to the Intensive Care unit between June 2015 and July 2017. Patients were divided into control, sepsis and septic shock groups, and their serum concentrations of PCT and related indicators of infection were compared. Results: PCT levels increased significantly from the control to the sepsis group and from the sepsis to the septic shock group $(P<0.01$ each). There were no significant differences in white blood cell (WBC) count, neutrophil percentage and body temperature among the groups $(P>0.05)$. Receiver operating curve $(R O C)$ analysis showed that the areas under the curve (AUC) for PCT, WBC count, neutrophil percentage and body temperature were $0.949,0.657,0.640$ and 0.656 , respectively. PCT, with $0.52 \mu \mathrm{g} / \mathrm{L}$ as the cut-off concentration, had the highest performance in the diagnosis of severe surgical sepsis, with a sensitivity of $96.1 \%$, a specificity of 92.3\% and a Youden index of 0.884 . Conclusion: PCT concentration is diagnostic of infection in severe surgical patients, has high specificity in the early diagnosis of sepsis, and can reflect the severity of infection.

Keywords: Serum procalcitonin, Infection, Sepsis, Diagnosis

Corresponding Author

Guixing Xu, Department of Critical Care Medicine, The First Affiliated Hospital, Sun Yat-sen University, Guangzhou, Guangdong, China.

Email: zjclassi@163.com

\section{How to Cite this Article}

Zheng D, Liu N, Ma J, Chen L, Tai Q, Xu G. The Role of Procalcitonin in the Diagnosis and Prognosis of Severe Surgical Patients with Sepsis. Int J Med Res Rev. 2019;7(2):92-97.

\section{Available From}

https://ijmrr.medresearch.in/index.php/ijmrr/article/ view/1042
To Browse

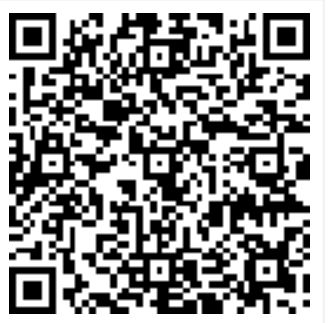

Manuscript Received 2019-03-20

Conflict of Interest No
Review Round 1 2019-03-30

Funding Nil

Review Round 2
2019-04-04
$\begin{gathered}\text { Ethical Approval } \\ \text { Yes }\end{gathered}$

Review Round 2 Yes
Review Round 3

Accepted 2019-04-08

Plagiarism X-checker $6 \%$
Note

(c) 2019 by Donghua Zheng, Na Liu, Jianhui Ma, Li Chen, Qiang Tai, Guixing Xu and Published by Siddharth Health Research and Social Welfare Society. This is an Ópen Access article licensed under a Creative Commons Attribution 4.0 International License https://creativecommons.org/licenses/by/4.0/ unported [CC BY 4.0]. 


\section{Introduction}

Sepsis is one of the main causes of death in severe surgical patients. Most of these patients are transferred to the ICU because of respiratory and circulatory instability. Qualified indicators of infection are required to determine and evaluate whether sepsis is complicated by systemic infection and the severity of sepsis.

Serum procalcitonin(PCT) has a higher specificity for bacterial infections [1]. And procalcitonin concentration are reliable markers of sepsis in the ICU, and PCT is more sensitive and are specific markers of sepsis as compared with serum Creactive protein, interleukin-6, and lactate levels [2].

However, the diagnostic value of PCT and its relationship with other common infection indicators (white blood cell count, neutrophil percentage and body temperature) are not very clear. This study evaluated the value of PCT concentration and other indicators of infection in the diagnosis of sepsis, enabling the clinical determination of early sepsis and the evaluation of disease prognosis.

\section{Materials and Methods}

Study design: The clinic study was conducted in the Department of Critical Medicine, The First Affiliated Hospital, Sun Yat-sen University after obtaining clearance from institutional ethics committee. Informed written consent was obtained from all individual participants included in the study. This was a retrospective study with a sample size of 77 patients.

Selection of subjects: Seventy-seven critically ill surgical patients meeting the standards of the American College of Chest Physicians and the Society of Critical Care Medicine and transferred from the Surgery Department to the Intensive Care Unit between June 2015 and July 2017 were included. Patients were divided into three groups: a sepsis group of 26 patients with a clear source of infection, and who conformed to the systemic inflammatory response syndrome standard; a septic shock group of 25 patients with sepsis, accompanied by multiple organ dysfunction or hypoperfusion of tissues and organs; and a control group of 26 patients with focal infection, who had undergone surgery or trauma without evidence of systemic infection, and who did not meet the diagnostic criteria of SIRS.
Exclusion criteria: Patients were excluded if only one day had elapsed after surgery or trauma; if they had been admitted to the ICU for less than 24 hours; or if inflammatory mediators were released when other drugs stimulated the cells. Patients with small cell lung cancer, rheumatic disease, acute embolic disease or chronic inflammatory response disease were also excluded.

Monitoring: Serum PCT concentration was measured using chemiluminescence analysis, which had a sensitivity of $0.01 \mu \mathrm{g} / \mathrm{L}$.

Statistics: SPSS 16.0 software was used for analysis. Normally distributed data were reported as mean \pm standard deviation ( $x \pm s$ ), with results in pairs of groups compared using unpaired t-tests. Non-normally distributed data were reported as the median (25th percentile [P25], 75th percentile $[\mathrm{P75}])$, with results in multiple groups compared by the Kruskal-Wallis test; if differences were significant, results in pairs of groups were compared by the Mann-Whitney $U$ test. The patients' working curves were drawn to analyze the diagnostic value of PCT, white blood cell (WBC) count, neutrophil percentage $(\mathrm{N} \%)$ and body temperature in severe surgical patients with sepsis and septic shock. $\mathrm{P}<$ 0.05 was considered statistically significant.

\section{Results}

General Situation:Infected sites among patients in this study ranged widely and included the lungs, abdomen, urinary tract, deep vein catheter, and limbs, with the majority in the lungs. Primary pathogenesis included severe brain injury, liver transplantation, kidney transplantation, lung abscess, multiple systemic injuries, right hepatectomy due to liver cancer, cerebral hemorrhage, bronchiectasis, severe acute pancreatitis, myasthenia gravis, postoperative brain tumor, perforation of the digestive tract, obstructive jaundice, postoperative gastric cancer, and abdominal aortic aneurysm.

\section{Comparison of Infection Indicators [13]}

Table 1 shows the median $\{\mathrm{P} 25, \mathrm{P} 75]$ number of infection indicators in the study cohort. PCT concentrations differed significantly in the control, sepsis and septic shock groups $(P<0.01)$. A repeat Mann-Whitney $U$ test indicated that the PCT concentrations in the three groups were in the order: control group < sepsis group < septic shock group. 
WBC, N\%, body temperature and other indicators did not differ significantly in these three groups.

Table-1: Indicators of Infection among Patients in the Control, Sepsis, and Septic Shock Group.

\begin{tabular}{|l|l|l|l|l|l|}
\hline & $\begin{array}{r}\text { Case } \\
\text { No. }\end{array}$ & \multicolumn{1}{|c|}{ PCT } & WBC count & \multicolumn{1}{|c|}{ N\% } & \multicolumn{1}{|c|}{$\begin{array}{l}\text { Body } \\
\text { Temperature }\end{array}$} \\
\hline $\begin{array}{l}\text { Control } \\
\text { Group }\end{array}$ & 26 & $\begin{array}{l}0.17 \\
(0.07,0.36)\end{array}$ & $\begin{array}{l}10.24 \\
(8.4,14.7)\end{array}$ & $\begin{array}{l}80.75 \\
(76.00,87.40\end{array}$ & $\begin{array}{l}37.0 \\
(36.5,37.5)\end{array}$ \\
\hline $\begin{array}{l}\text { Sepsis } \\
\text { Group }\end{array}$ & 26 & $\begin{array}{l}1.62 \\
(1.01,2.11)\end{array}$ & $\begin{array}{l}13.39 \\
(10.84,15.64\end{array}$ & $\begin{array}{l}86.50 \\
(79.8,90.10)\end{array}$ & $\begin{array}{l}37.7 \\
(36.8,38.5)\end{array}$ \\
\hline $\begin{array}{l}\text { Septic Shock } \\
\text { Group }\end{array}$ & $\begin{array}{l}16.00 \\
(4.73,81.61\end{array}$ & $\begin{array}{l}16.08 \\
(11.24,23.51\end{array}$ & 87.00 & $(81.00,90.30$ & 38.0 \\
$(36.8,38.7)$
\end{tabular}

Results reported as Median [p25, p75]

Abbreviations: $\mathrm{PCT}$, procalcitonin; WBC, white blood cell; N\%, percent neutrophils

ROC curve analysis evaluating the ability of various infection indicators to diagnose sepsis [7]

The ROC curves were drawn based on the PCT concentration, WBC count, N\% and body temperature of the sepsis group (including the sepsis and septic shock groups) and the control group. The ROC curves were used to analyze the value of PCT, WBC count, N\% and body temperature in the diagnosis of severe surgical sepsis (See Figure1). In addition, the area under the curve (AUC), standard error and 95\% confidence interval (CI) of each indicator (see Table 3) were analyzed from ROC curves. The optimal cut-off point, sensitivity, specificity and Youden index of each infection index were also calculated based on the ROC curves (see Table 4).

Table-2: Kruskal Wallis Test.

\begin{tabular}{|l|c|l|l|l|}
\hline & PCT & WBC & N\% & \multicolumn{1}{|c|}{ Body Temperature } \\
\hline Chi-Square & 56.99 & 5.63 & 4.11 & 5.35 \\
\hline P Value & 0.001 & 0.060 & 0.128 & 0.069 \\
\hline
\end{tabular}

Table-3: AUC, Standard Error, and 95\% CI for PCT concentration, WBC count, N\%, and Body temperature in the diagnosis of sepsis.

\begin{tabular}{|l|l|l|l|l|l|}
\hline & AUC & $\begin{array}{c}\text { Std. } \\
\text { Error }\end{array}$ & PValue & \multicolumn{1}{|c|}{$\begin{array}{c}\text { 95\% CI Lower } \\
\text { Bound }\end{array}$} & $\begin{array}{c}\text { Upper } \\
\text { Bound }\end{array}$ \\
\hline PCT & 0.949 & 0.030 & 0.000 & 0.889 & 1.008 \\
\hline WBC & 0.657 & 0.065 & 0.025 & 0.530 & 0.784 \\
\hline N\% & 0.640 & 0.069 & 0.045 & 0.505 & 0.776 \\
\hline Temperature & 0.656 & 0.062 & 0.026 & 0.534 & 0.778 \\
\hline
\end{tabular}

Table-4: Optimal Cut-off Point, Sensitivity, Specificity and Youden Index of PCT concentration, WBC count, N\% and Body Temperature in the Diagnosis of Sepsis.

\begin{tabular}{|l|l|l|l|l|}
\hline & $\begin{array}{c}\text { Optimal Cut-off } \\
\text { Point }\end{array}$ & $\begin{array}{c}\text { Sensitivity } \\
\%\end{array}$ & $\begin{array}{c}\text { Specificity } \\
\%\end{array}$ & $\begin{array}{c}\text { Youden } \\
\text { Index }\end{array}$ \\
\hline PCT $(\mu \mathrm{g} / \mathrm{L})$ & 0.52 & 96.1 & 92.3 & 0.884 \\
\hline WBC $(10 \mathrm{E} / \mathrm{L})$ & 10.68 & 78.4 & 53.8 & 0.323 \\
\hline N $(\%)$ & 77.9 & 88.2 & 61.5 & 0.267 \\
\hline $\begin{array}{l}\text { Temperature } \\
\left({ }^{\circ} \mathrm{C}\right)\end{array}$ & 37.7 & 54.9 & 84.6 & 0.395 \\
\hline
\end{tabular}

\section{Discussion}

Patients with severe surgical diseases who are admitted to the Intensive Care Unit (ICU) may be exacerbated into sepsis or septic shock. Sepsis is reported to be the most common cause of death in non-coronary ICU. It is an increasingly common cause of mortality and morbidity particularly in elderly, Immunocompromised and critically ill patients. $25-35 \%$ of patients with severe sepsis die within 30 days.

Therefore, the early diagnose of sepsis is important[15]. Methods, including a qualified index of infection, are needed to diagnose sepsis, enabling clinicians to search for the source of infection and to apply surgical infection drainage as well as administer antibiotics in a timely fashion. This can result in the survival of higher percentages of surgical patients in critical conditions [3].

The white blood cell (WBC) count was used as the indicator of the infection many years ago. Normally the total WBC count for an adult ranges from 5,000 to $10,000 / \mathrm{mm} 3$. Leukocytosis (WBC $>10,000 / \mathrm{mm} 3$ ) can indicate infection, inflammation (possibly from allergies), tissue damage or burns, dehydration, thyroid storm, leukemia, stress, or steroid use. In the most case, infections result in the leukocytosis.

The degree of leukocytosis depends on the severity of the disorder, the patient's age and general health, and bone marrow health.In contrast, leukopenia (WBC $<4,000 / \mathrm{mm} 3$ ) can indicate a viral infection or some bacterial infections, including overwhelming ones; bone marrow failure; collagen or vascular diseases such as lupus; liver or spleen disease; radiation; drug toxicity; autoimmune disease; or dietary deficiency, such as vitamin B12 deficiency.

However, the abnormal WBC count doesn't mean the infection, as well as sepsis [14]. 
The WBC count, neutrophil percentage and body temperature are traditional inflammation indices frequently used in clinical studies. These markers, can be easily obtained from the clinic, and the dynamic monitoring about them is also relate to the severity of the sespis in the critical ill patients. However, they are unable to distinguish between infectious and non-infectious diseases. Moreover, the sensitivity and specificity of these methods are suboptimal, preventing their use in diagnosing sepsis, as well as in determining prognosis [4].

PCT, first described in 1993 as an early marker of bacterial infection, has been utilized as an indicator of inflammation, including in the differential diagnosis of infectious diseases [6]. Serum PCT, normally produced in the C-cells of the thyroid gland, is the precursor of calcitonin. A specific protease cleaves serum PCT to calcitonin, catacalcin, and an $\mathrm{N}$-terminal residue.

Normally, all serum PCT is cleaved and none is released into the blood stream. Serum PCT levels are therefore undetectable $(<0.1 \mathrm{ng} / \mathrm{ml})$ in healthy humans. During severe infections with systemic manifestations, however, serum PCT levels may increase to over $100 \mathrm{ng} / \mathrm{ml}$. In these conditions, serum PCT is probably produced by extra-thyroid tissues $[16,17]$.

Serum PCT levels increase during severe generalized bacterial, parasitic or fungal infections with systemic manifestation. In severe viral infections, or inflammatory reactions of noninfectious origin, serum PCT levels do not increase or only show a moderate increase [18]. So PCT has been reported to be a more accurate reflector of inflammatory factor variation than traditional markers.

PCT concentrations increase slightly in patients with non-infectious diseases, such as neoplastic fever, rheumatic immune diseases, and inflammatory reactions caused by surgical trauma. In patients with systemic bacterial, fungal and parasitic infections, however, PCT levels are abnormally high, with the extent of increase associated with the severity of the infection [9].

The results of the present study indicated that PCT levels differed significantly among the control, sepsis and septic shock groups $(P<0.01)$, in the order control < sepsis < septic shock. Thus, a higher PCT level was associated with a greater possibility of septic shock, a higher mortality rate and a poorer prognosis.
Use of ROC curve analysis to evaluate the utility of inflammatory indicators commonly used in the early clinical diagnosis of sepsis showed that the AUC of PCT concentration was significantly higher than that of other inflammatory indicators (WBC count, neutrophils percentage, and body temperature). ROC curve analysis showed that the optimal PCT cut-off point distinguishing sepsis from noninfectious diseases was $0.52 \mu \mathrm{g} / \mathrm{L}$. PCT was found to have a sensitivity of $96.1 \%$ and a specificity of $92.3 \%$, suggesting that PCT has a high value for early diagnosis [8].

The overuse of antibiotic agents is a public health problem1 associated with in- creased health care costs and antibiotic resistance. PCT level is associated with the severity of the infection. The effects of antibiotics for treatment of sepsis can be assessed by monitoring PCT level, determining whether antibiotics should be continued or changed. PCT-guided decision making for suspected earlyonset sepsis can safely reduce the duration and the using dosages of antibiotic treatment $[5,10,11]$.

Our study had some limitations. More samples were better to analysis the data. In some particular cases acute kidney injury patients), high procalcitonin levels are a marker of acute kidney injury but will not be better to differentiate infected from noninfected patients. PCT is partly eliminated in the urine and the amount eliminated was reduced in patients with impaired renal function [12]. The strategy still needs further validation in large prospective studies.

In conclusion, PCT plays an important role in the diagnosis of sepsis, and it is the crucial indicator for infection. The high procalcitonin levels are related to the severity of sepsis. When compared with infection indicators such as WBC count, neutrophil percentage and body temperature, PCT has obvious advantages with the sensitivity and specificity while it is used in the diagnosis of sepsis in ICU. PCTguided decision making for suspected sepsis will be more useful for the clinic in the future[19,20].

\section{Contribution by authors}

01. Dr. Donghua Zheng, Na Liu,- data collection and preparing the manuscript

02. Dr. Jianhui Ma, Li Chen, QiangTai,- methodology preparation and helping inmanuscript writing

03. Dr Guixing Xu- statistical analysis and deriving statistical inference 


\section{What this study add to existing knowledge}

PCT has come into general application for sepsis in ICU and it can control the overuse of antibiotic treatment.

\section{Reference}

01. TheerasukKawamatawong, Wisarn Jintanalert. Serum procalcitonin (PCT-Q) as a diagnostic tool for bacterial lower respiratory tract infection among COPD patients with acute exacerbation. European Respiratory Journal. 2013;42;P2072. [Crossref]

02. Müller $B$, Becker $K L$, Schächinger $H$, et al. Calcitonin precursors are reliable markers of sepsis in a medical intensive care unit. Crit Care Med. 2000 Apr;28(4)977-83.

[Crossref]

03. Rajkumari N, Mathur $P$, Sharma $S$, et al. Procalcitonin as a predictor of sepsis and outcome in severe trauma patients- a prospective study. J Lab Physicians. 2013 Jul; 5(2)100-8.

doi: 10.4103/0974-2727.119852 [Crossref]

04. Jolivet P, Christen G, Seematter G, et al. Usefulness of biomarkers of sepsis in the ICU. Rev Med Suisse. 2011 Dec 14;7(321)2430-4. [Crossref]

05. Layios N, Lambermont B. Procalcitonin for antibiotic treatment in intensive care unit patients. Curr Infect Dis Rep. 2013 Oct; 15(5)394-9.

doi: 10.1007/s11908-013-0360-2 [Crossref]

06. Assicot M, Gendrel D, Carsin H, et al. High serum procalcitonin concentrations in patients with sepsis and infection. Lancet. 1993 Feb 27;341(8844)515-8.

[Crossref]

07. Sakran JV, Michetti CP, Sheridan MJ, et al. The utility of procalcitonin in critically ill trauma patients. J Trauma Acute Care Surg. 2012 Aug;73(2)413-8.

doi: $10.1097 /$ TA.0b013e31825ff5b7 [Crossref]
08. Nandini Mahadev, Shoukath Abdul Raheem, et al. A study of serum procaltitom in (PCT) as a diagnostic biomarker in sepsis in ICU. Journal of Evidence Based Medicine and Healthcare. 4(13)2017;730-734(5).

[Crossref]

09. Vincent JL, Van Nuffelen M, et al. Host response biomarkers in sepsis: the role of procalcitonin. Methods Mol Biol. 2015;1237;213-24.

doi: 10.1007/978-1-4939-1776-1_16 [Crossref]

10. Stocker $M$, van Herk W, El Helou S, et al. Procalcitonin- guided decision making for duration of antibiotic therapy in neonates with suspected early-onset sepsi- a multicentre, randomised controlled trial (NeoPIns). Lancet. 2017 Aug 26;390(10097)871-881.

doi: $10.1016 / S 0140-6736(17) 31444-7$ [Crossref]

11. Huang DT, Yealy DM, Filbin MR. Procalcitonin-Gui ded Use of Antibiotics for Lower Respiratory Trac t Infection. N Engl J Med. 2018;379(3)236-49. doi: $10.1056 /$ NEJMoa1802670 [Crossref]

12. Heredia-Rodríguez M, Bustamante-Munguira J, Fierro I, et al. Procalcitonin cannot be used as a biomarker of infection in heart surgery patients with acute kidney injury. J Crit Care. $2016 ; 33 ; 233-9$.

doi: $10.1016 /$ j.jcrc.2016.01.015 [Crossref]

13. Luzzani A, Polati E, Dorizzi R, et al. Comparison of procalcitonin and C-reactive protein as markers of sepsis. Crit Care Med. 2003 Jun;31(6)1737-41.

DOI: $\quad$ 10.1097/01.CCM.0000063440.19188.ED [Crossref]

14. George EL, Panos A. Does a high WBC count signal infection?. Nursing. 2005 Jan;35(1)20-1. [Crossref]

15. Hotchkiss RS, Moldawer LL, Opal SM, et al. Seps is and septic shock. Nat Rev Dis Primers. 2016;2;16045. doi: 10.1038/nrdp.2016.45 [Crossref]

16. Becker $\mathrm{KL}$, Nylén ES, White JC, et al. Clinical review 167- Procalcitonin and the calcitonin gene family of peptides in inflammation, infection, and sepsis- a journey from calcitonin back to its precursors. J Clin Endocrinol Metab. 2004 Apr;89(4)1512-25.

DOI: $10.1210 /$ ic. 2002-021444 [Crossref] 
17. Kopterides $\mathrm{P}$, Tsangaris I. Procalcitonin and sepsis- recent data on diagnostic utility prognostic potential and therapeutic implications in critically ill patients. Minerva Anestesiol. 2012 Jul;78(7)823-35.

[Crossref]

18. Meisner M. Pathobio chemistry and clinical use of procalcitonin. Clin Chim Acta. 2002Sep;323(1-2)17-29.

[Crossref]
19. Hohn A, Schroeder S, Gehrt A, et al. Procalcitonin-guided algorithm to reduce length of antibiotic therapy in patients with severe sepsis and septic shock. BMC Infect Dis. 2013 Apr $1 ; 13 ; 158$.

doi: $10.1186 / 1471-2334-13-158$ [Crossref]

20. Bloos F, Trips E, Nierhaus A, et al. Effect of Sodium Selenite Administration and Procalcitonin-Guided Therapy on Mortality in Patients With Severe Sepsis or Septic Shock- A Randomized Clinical Trial. JAMA Intern Med. 2016 Sep $1 ; 176(9) 1266-76$.

doi: 10.1001/jamainternmed.2016.2514 [Crossref] 